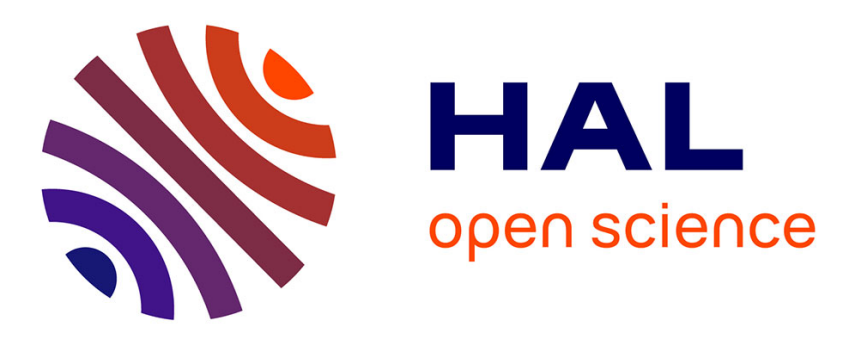

\title{
The potential of inertial sensors in posture, gait and cycling FES-assistance
}

Christine Azevedo Coste, Benoît Sijobert, Christian Geny, Jérôme Froger, Charles Fattal

\section{- To cite this version:}

Christine Azevedo Coste, Benoît Sijobert, Christian Geny, Jérôme Froger, Charles Fattal. The potential of inertial sensors in posture, gait and cycling FES-assistance. ICNR: International Conference on NeuroRehabilitation, Oct 2016, Ségovie, Spain. pp.699-704, 10.1007/978-3-319-46669-9_115 . lirmm-01375373

\section{HAL Id: lirmm-01375373 https://hal-lirmm.ccsd.cnrs.fr/lirmm-01375373}

Submitted on 3 Oct 2016

HAL is a multi-disciplinary open access archive for the deposit and dissemination of scientific research documents, whether they are published or not. The documents may come from teaching and research institutions in France or abroad, or from public or private research centers.
L'archive ouverte pluridisciplinaire HAL, est destinée au dépôt et à la diffusion de documents scientifiques de niveau recherche, publiés ou non, émanant des établissements d'enseignement et de recherche français ou étrangers, des laboratoires publics ou privés. 


\title{
The potential of inertial sensors in posture, gait and cycling FES-assistance
}

\author{
Christine Azevedo Coste $*^{1}$, Benoît Sijobert ${ }^{1}$, Christian Geny ${ }^{2}$, Jérôme Froger ${ }^{3}$ and Charles Fattal ${ }^{4}$
}

\begin{abstract}
In this communication we will present some general approaches developed in our team and recent results involving inertial measurement units (IMU) in FES-controllers for lower-limb movement assistance in different situations of sensory-motor deficiencies. We will discuss some of the challenges to met in order to achieve robust adaptive controllers.
\end{abstract}

\section{INTRODUCTION}

Online modulation of electrical stimulation (ES) parameters in the context of lower limb function assistance requires the availability of information about the ongoing movement. Different levels of complexity can be considered, going from simple open-loop to complex control laws. In this communication we will illustrate the potential of using Inertial Measurement Units (IMU) in this context through several applications involving surface ES (figure 11).

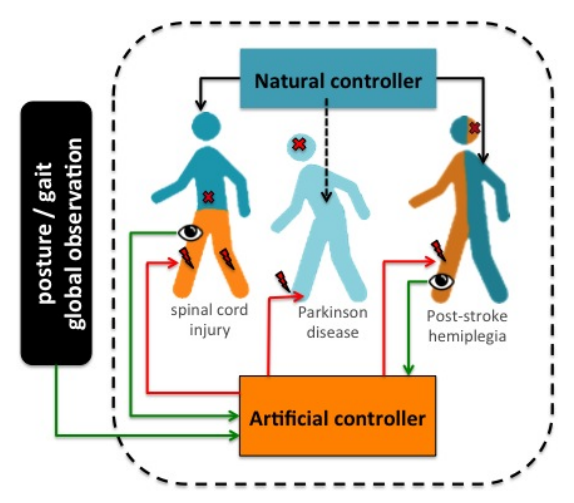

Fig. 1. FES-assistance should consider the co-existence of artificial and natural controllers. Artificial controllers should integrate both global (posture/gait) and local (limb/joint) observations. 3 situations will be considered in the following: paraplegia, Parkinson Disease and post-stroke hemiplegia.

\section{Parkinson Disease gait assistance}

We have explored the possibility to use ES as a cueing procedure in Parkinson's Disease (PD) [4]. PD is a neurodegenerative disorder associated to various symptoms including tremor, bradykinesia, gait impairments with an increased risk of falls [3] and in some cases, freezing of gait (FOG). FOG can be defined as a sudden absence or reduction of feet movement despite the intention to walk. Visual and auditory stimuli have been reported as cueing methods able to reduce occurrence and duration of FOG events and to improve gait. We have stimulated, at a comfortable yet sensitive intensity,

\footnotetext{
* contact: christine.azevedo@inria.fr

1 INRIA / LIRMM, Montpellier, France

2 CHU Montpellier- EUROMOV, Montpellier, France

3 CHU Nîmes/Montpellier - EUROMOV, Montpellier, France

4 CRF COS Divio, Dijon, France
}

the arch of the foot of 13 subjects with PD. An inertial sensor was attached to the stimulated foot. The pre-programmed stimulation pattern was triggered at heel-off. Heel-off time was associated to non-stationary period of the angular speed obtained from the IMU. The principle is to provide the subjects with an information on when to lift their leg. After a short familiarization to electrical stimulation, subjects were instructed to walk on a predefined path (fig 2). 2 conditions were compared: absence or presence of ES cueing.

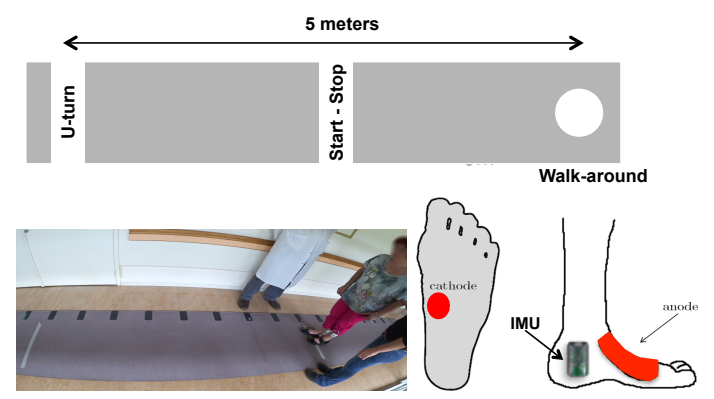

Fig. 2. Description of the protocol developed to study the benefits of electrical stimulation as a cueing mean to improve gait in Parkinson Disease.

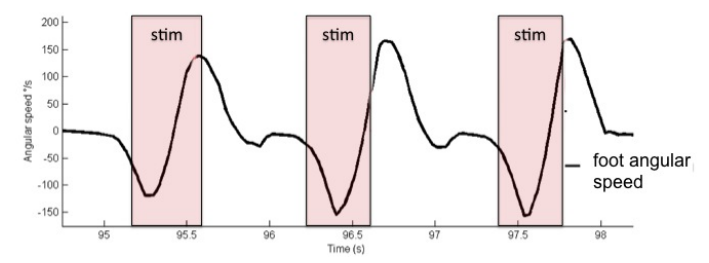

Fig. 3. Estimation of heel-off phases using inertial measurement unit located on the foot to electrically stimulate.

We observed that ES cueing globally decreased of $12 \%$ FOG occurrence compared to baseline without ES cueing. ES cueing also improved gait performances: reduction of time needed to perform u-turn ( $15 \%$ reduction), time needed to cover the 5-m straight distance ( $14 \%$ reduction) and time needed to perform the walk-around task ( $19 \%$ reduction). In the future we will test different trigger strategies based on information extracted from IMU. We have in the past proposed a freezing of gait detection algorithm, based on inertial sensor data [2] that could be one of the approaches.

\section{Post-STROKE HEMIPLEGIA DROP-FOOT CORRECTION}

Drop-foot syndrome is a gait impairment that affects stroke survivors. Electrical stimulators have been proposed to correct gait and prevent foot dragging on the ground through the activation of the common peroneal nerve, eliciting ankle dorsiflexion during swing phase. Dropped foot stimulators 
are usually based on a pre-programmed electrical stimulation pattern triggered by heel-off detection from a force sensing resistor heel switch placed in the shoe of the affected side. Other approaches have been proposed to trigger the stimulation patterns such as event detection based on tilt sensors signal [6]. Real-time adaptation of stimulation pattern is still not available in existing devices. The modulation of ES parameters optimizing the delivered dorsiflexion assistance in the presence of fatigue or to adapt to context (stairs, sand, slopes...) would be of high potential to users [1]. Adaptive controllers need the availability of information on movement execution and environmental changes. A minimum number of sensors with a minimal impact on patient motions is necessary. In a previous work we have proposed to continuously track gait cycle execution from a single sensor placed on the shank of subjects [5]. In this approach, walking gait is represented by the shank tilt angle which behavior is modeled by a non-linear oscillator. A state observer of this system allows to estimate the phase of the oscillator (figure 4). This approach has been tested in 20 post-stroke hemiplegic survivors. The delivery of stimulation from a dropfoot electrical stimulator was triggered based on the estimated phase of the oscillator. A complete information on the gait cycle evolution can

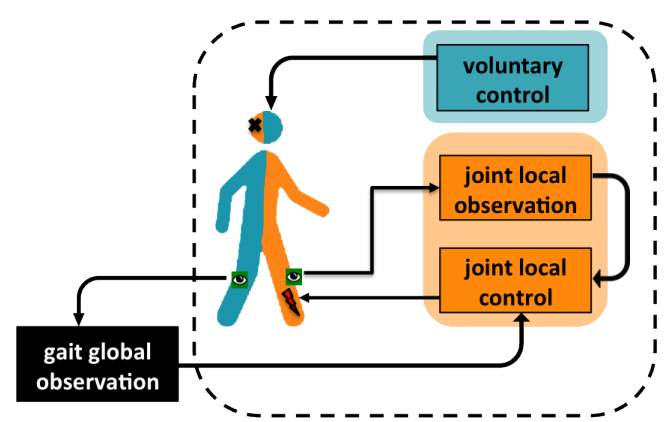

Fig. 4. Drop foot correction general approach description. Global observation of gait is associated to local observation to adapt delivered stimulation pattern parameters and time profile to sensory feedback.

be extracted from one single sensor placed on the shank of one leg, i.e a global knowledge on the task realization. This global observation of movement (fig 4 ) gives the possibility to trigger pre-programmed stimulation patterns at any point of the gait cycle inclusively before the occurrence of gait events. Other types of global observation information can be extracted from the inertial sensor such as: stride length, gait cadence, foot clearance... [7], [8] Complementary to a global observation of gait, a local information about the executed movement such as joint angle will be soon used to modulate the stimulation parameters [9].

\section{Complete PARAPLEgia CYCLING ASSiSTANCE}

FES-assisted cycling is one of the possible areas where inertial sensors can be integrated to increase adaptability of control laws. Stimulating lower limb muscles of complete spinal cord injured individuals (SCI) can elicit pedaling movements and propel a trike cycle (fig 5). Usually crank sensors are used to trigger pre-programmed stimulation patterns: depending on pedal positions different muscles are stimulated in the 2 legs. IMU can give extra information (angle speed, accelerations) and be used to adapt the stimulation profiles. Ongoing developments in our team are trying to take benefit of inertial sensors potential to improve performance of cycling in the context of Cybathlon competition [10].

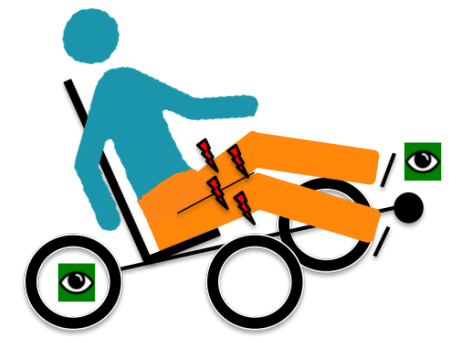

Fig. 5. FES-cycling could benefit from inertial sensor measurements.

\section{CONCLUSION}

In this communication we intend to present the potential of using inertial sensors within FES-controllers. Inertial measurement units (IMU) are considered here in a single sensor version but body area network (BAN) versions are also possible. Our intention is to illustrate different situations where information extracted form IMU can be used to trigger pre-programmed stimulation or to adapt stimulation profiles. Some preliminary results obtained in our team will be presented to show the potential of this approach. Most of the concepts described here could be adapted to other assistive techniques (orthoses, exoskeletons...) or to hybrid approaches associating active orthotic devices with ES.

\section{REFERENCES}

[1] Ch. Azevedo Coste, B. Sijobert, J. Froger and Ch. Fattal, "Preliminary developments towards closed-loop FES-assistance of posture and gait," in $\{I F A C\}$ Symposium on Biological and Medical Systems $\{B M S\}$, Berlin, Germany, 2015, pp333-337.

[2] C. Azevedo Coste, B. Sijobert, R. Pissard-Gibollet, M. Pasquier, B. Espiau and C. Geny, "Detection of freezing of gait in Parkinson disease: preliminary results.", in Sensors, vol.14, no.4, 2014.

[3] B. R. Bloem, J. M. Hausdorff, J. E. Visser, and N. Giladi, Falls and freezing of Gait in Parkinsons disease: A review of two interconnected, episodic phenomena, Mov. Disord., vol.19, no.8, pp. 871884, 2004.

[4] B. Sijobert, C. Azevedo, D. Andreu, C. Verna and C. Geny, "Effects of sensitive electrical stimulation based cueing in Parkinson's disease: preliminary study.", in International Functional Electrical Stimulation Society (IFESS) conference, 2016.

[5] C. Azevedo Coste, J. Jovic, R. Pissard-Gibollet, and J. Froger, "Continuous gait cycle index estimation for electrical stimulation assisted foot drop correction.", in Journal of NeuroEngineering and Rehabilitation, vol. 11 , no. $1,2014$.

[6] D. Everaert, R. Stein, G. Abrams, A. Dromerick, G. Francisco, B. Hafner, T. Huskey, M. Munin, K. Nolan and C. Kufta, "Effect of a foot-drop stimulator and ankle-foot orthosis on walking performance after stroke: a multicenter randomized controlled trial.", in Neurorehabilitation and Neural Repair, vol.27, no.7, 2013.

[7] M. Benoussaad, B. Sijobert, K. Mombaur and C. Azevedo Coste, "Robust Foot Clearance Estimation Based on the Integration of FootMounted IMU Acceleration Data," in Sensors, vol.16, no.1 2016.

[8] B. Sijobert, M. Benoussaad, J. Denys, R. Pissard-Gibollet, C. Geny, C. Azevedo Coste, "Implementation and Validation of a Stride Length Estimation Algorithm, Using a Single Basic Inertial Sensor on Healthy Subjects and Patients Suffering from Parkinsons Disease." in Health, Vol.7, no.6, 2015.

[9] M. Benoussaad, K. Mombaur and C. Azevedo Coste, "Nonlinear Model Predictive Control of Joint Ankle by Electrical Stimulation For Drop Foot Correction.", in IEEE/RSJ International Conference on Intelligent Robots and Systems (IROS'13), 2013.

[10] http://www.cybathlon.ethz.ch/ 